\title{
RECOVERY CAPABILITY OF MULTIFILAMENTARY \\ SUPERCONDUCTORS WITH NON-UNIFORM VOID DISTRIBUTION
}

\author{
A. Y, LEE
}

(w. Westinghouse Electric Corporation P.O. Box 10864, Pgh. Pa. 15236

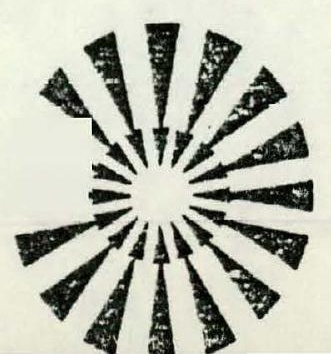




\section{DISCLAIMER}

This report was prepared as an account of work sponsored by an agency of the United States Government. Neither the United States Government nor any agency Thereof, nor any of their employees, makes any warranty, express or implied, or assumes any legal liability or responsibility for the accuracy, completeness, or usefulness of any information, apparatus, product, or process disclosed, or represents that its use would not infringe privately owned rights. Reference herein to any specific commercial product, process, or service by trade name, trademark, manufacturer, or otherwise does not necessarily constitute or imply its endorsement, recommendation, or favoring by the United States Government or any agency thereof. The views and opinions of authors expressed herein do not necessarily state or reflect those of the United States Government or any agency thereof. 


\section{DISCLAIMER}

Portions of this document may be illegible in electronic image products. Images are produced from the best available original document. 


\section{RECOVERY CAPABILITY OF MULTIFILAMENTARY SUPERCONDUCTORS WITH NON-UNIFORM VOID DISTRIBUTION}
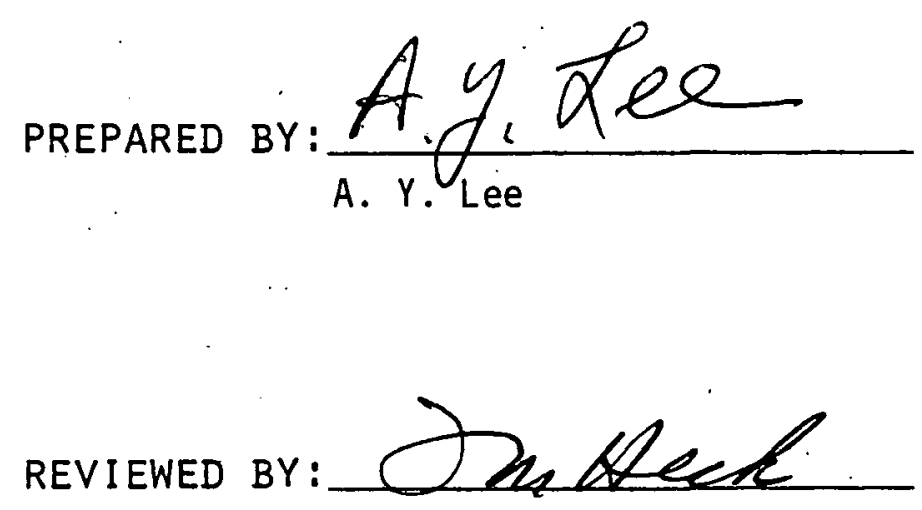

F. M. Heck, Manager

Systems Engineering

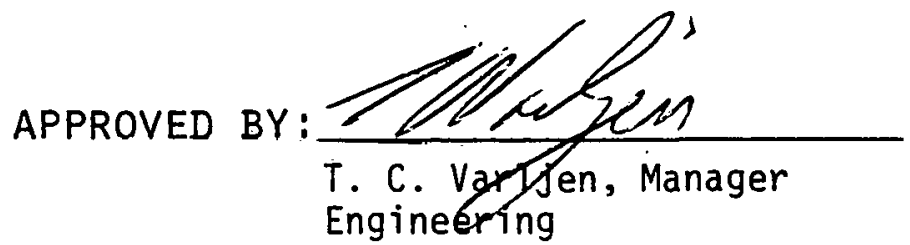

Engineering

\section{fusion pouter systems department \\ (w) Westinghouse Electric Corporation P.O. Box 10004, Pign. Pa. 1529.

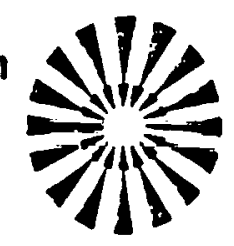




\section{ACKNOWLEDGEMENT}

This work was performed for the Office of Fusion Energy of the U.S. Department of Energy under Contract 22×3147C on the Large Coil Program, a program undertaken by the Large Rotating Apparatus Division of Westinghouse Electric Corporation. Reproduction, translation, publication, use and disposal, in whole or in part, by or for the United States Government is permitted.

\section{LEGAL NOTICE}

This report was prepared as an account of Government sponsored work. Neither the United States, nor the Department of Energy, nor any person acting on behalf of the Department:

A. Makes any warranty or representation, expressed or implied, with respect to the accuracy, completeness, or usefulness of the information contained in this report, or that the use of any information, apparatus, method or process disclosed in this report may not infringe privately owned rights; or

B. Assumes any liabilities with respect to the use of, or for damages resulting from the use of any information, apparatus, method, or process disclosed in this report.

Printed in the United States of America Available from

National Technical Information Service U.S. Department of Commerce 5285 Port Royal Road Springfield, VA 22161

Price: Printed Copy $\$ 3.50$; Microfiche $\$ 3.00$ 


\section{AESTRACT}

The effects of several abnormal conditions resulting from a possible non-uniform void distribution in a multifilamentary and cabled superconductor on the cryogenic recovery capability of a triplex, a seven strand bundle and a 19 strand bundle were studied. For a triplex, if only one of the three strands was cooled, the maximum recoverable initial normal temperature is reduced by $1 / 3$ of the value for the nominal case in which all the three strands are cooled equally. If the outer six strands of a seven strand bundle were cooled and the center one was not cooled, the recovery capability of this bundle is just slightly below that of the nominal triplex. If only the outer 12 strands of a 19 strand bundle were cooled, the bundle would not recover once it is driven normal. The effects of the cold and stagnant helium located in the space between the strands and of the insulation thickness are small.

\subsection{INTRODUCTION}

Multifilamentary and cabled superconductor composites are now being developed and designed to be used in the large scale magnetic coils of future fusion reactors and long distance transinission cables. The particular analysis reported here was performed in support of tokamak fusion-hybrid studies. The basic subcables of such a superconductor are the twisted triplexes. Many transposed triplexes are then compacted and encapsulated inside a metal jacket to form a conductor. The conductor is to be cooled by forced flow single phase supercritical liquid helium along the interstices between the composite strands.

The superconductors are designed to be cryostable. This requires that the superconductor must be able to recover its superconductivity spontaneously, after the occurence of an event in which a quantity of heat is suddenly deposited in the composite. If the heat is sufficiently high, the composite would be driven to the normal state whereby Joule heating is generated. The cooling system must then be designed to remove the heat generated for the conductor to recover its superconductivity.

Extensive cryostability analyses for this type of superconductor design and the cooling method have been carried out. References (1) to (4) are some examples. The stability analyses were mostly performed based on an idealized mudel in which all strands were assumed to be cooled equally. The model thus consists of a single lumped mass representing the solid materials - superconductor and substrate, having the nominal values of the heat transfer and coolant flow areas. Because of the method of construction of such multifilamentary cable, namely the twisting, transposing, compacting and bending, the void distribution inside the cable jacket of the final product would tend to be non-uniform. In some regions at any one cross section the void may be very small, so that some strands may not receive sufficient cooling. Fig. I shows a typical photograph of a cross section from a saimple cable consisting of about 400 strands. The outer dimension of the cable is about $2 \times 2 \mathrm{~cm}$ and the diameter of the strands is about $1 \mathrm{~mm}$. The white dots are the composite strands, the black areas are the void areas, and the white peripheral wall is the stainless steel jacket of the cable. It is seen from this photograph that many strands are grouped very closely together where the void area becomes much less than the average.

Manuscript received September 28, 1978.

*Westinghouse Electric Corporation, Fusion Power Systems Department, P. 0. Box 10864, Pit.t.sburgh. PA 15236

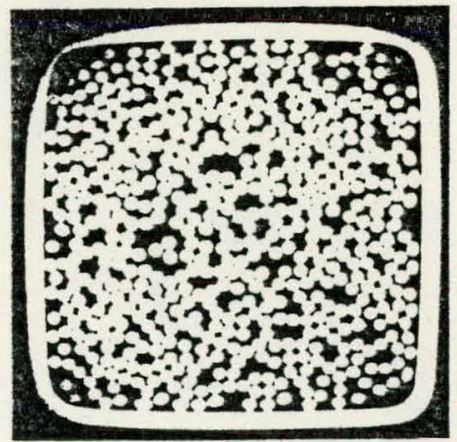

Fig. 1. Cross section of a typical multifilamentary and cabled superconductor.

The purpose of this paper is to present the results of a stability analysis in which a triplex, a 7 strand bundle and a 19 strand bundle were analyzed. The cryogenic recovery capabilities of each of these groups of strands were determined, when some of the strands within the group did not receive any cooling at all. The effects of the heat capacity of the cold and stagnant helium inside the dead space between the strands and of the insulation thickness around each of the strands were also studied.

\subsection{METHOD OF ANALYSIS}

The analysis considers the heat balance equations at a cross section of the strands and of the helium coolant. Neglecting the fluid flow and the axial heat conduction, the following equations were solved:

$$
\begin{aligned}
& \text { Strands: } \rho C_{p} \frac{\partial T}{\partial t}=\frac{\partial}{\partial x}\left(K \frac{\partial T}{\partial x}\right)+\frac{\partial}{\partial y}\left(K \frac{\partial T}{\partial y}\right)+Q^{\prime \prime} \\
& \text { and } K \frac{\partial T}{\partial n}=h\left(T-T_{H e}\right)=Q \text { o channel wall } \\
& \text { Helium: } \frac{d(\rho H)}{d t}=\frac{Q P}{A_{f}}
\end{aligned}
$$

where $T$ and $T_{H}$ are the temperatures of the conductor material and helium, respectively; $\rho, C_{p}$ and $k$ are the density, specific heat at constant pressure and thermal conductivity, respectively; $h$ is the neat lransfer coefficient and $H$ the enthalpy of the helium, $A_{f}$ is the helium flow area; $P$ is the wetter perimeter; $Q$ and $Q^{\prime \prime}$ are the heat flux and internal heat generation rate, respectively. Temperature dependent thermal properties of the solid materials and of the helium and the current sharing characteristic between the superconductor and the substrate are included in the analysis. The Joule heating term, Q'"' is determined by the following expression:

$$
Q^{\prime \prime \prime}=\frac{I \times I_{c u} \times \rho_{c u}}{{ }_{{ }_{C}} A_{c}{ }^{2}}
$$

where $I$ is the transport current; $I_{C U}$ is the current in the copper substrate; $\rho_{\mathrm{Cu}}$ is the copper resistivity; $f_{c}$ is the fraction of copper in the conductor and $A_{c}$ is the conductor area. The current in the copper, I $\mathrm{Cu}$ is determined by an approximately linear relationship 
between the superconductor current density and temperature as shown below:

$$
\begin{array}{ll}
I_{C U}=I, & \text { if } T \geq T_{c r} \\
I_{c u}=I\left(\frac{T-T_{C S}}{T_{c r}-T_{c s}}\right), & \text { if } T c s<T<T_{c r} \\
I_{c u}=0, & \text { if } T \leq T_{c s}
\end{array}
$$

where $T_{c r}$ is the critical temperature of the superconductor and $T_{c s}$ is the threshold temperature above which current sharing begins. Both $T_{c r}$ and $T_{c s}$ depend on the operating magnetic field and the operating transport current I.

The heat conduction equation, Equation (1) with boundary condition, Equation (2) are solved by an implicit finite difference procedure. Each strand in the model can be represented by one or more nodal points. The nelium coolant is represented, however, by one fluid node. The temperature rise of the helium is computed by the enthalpy change due to the heat addition as shown by Equation (3). The pressure and the flow rate are considered constant as specified in the input. The flow rate is used to determine the heat transfer coefficient by means of the Giarratano correlation(5), which was developed for a round and smooth tube. A multiplier of 1.5 was, therefore, applied to the heat transfer coefficient obtained from this correlation to account for the enhancement of heat transfer due to the cabling of the strands. The 50\% increase in heat transfer may be still conservative in view of the recent experimental results of Hoenig $(6)$. The test data showed a remarkable recovery capability at very low coolant flow.

The model of analysis for the triplex is shown in Fig. 2(a) in which each strand is represented by one material node. The strand average temperatures $T_{1}, T_{2}$ and $T_{3}$ and the strand wall temperatures $T w_{1}, T_{2}$ and $\mathrm{TW}_{3}$ were computed. The temperature of the stagnant helium located between the three strands was also computed. The heat transfer perimeter at each strand is only $5 / 6$ of the circumference of a strand. The contact arc length between two adjacent strands was assumed to be $1 / 10$ of the strand circumference due to compaction. The insulation thickness around one strand was simulated by an equivalent thermal resistance and added to the conduction resistances between the strands: The model for the seven strand bundle is shown in Fig. 2(b) in which the seven individual strands and the corresponding seven wall temperatures were computed. In this model, strand No. $l$ is not cooled. The model for $1 / 6$ of the 19 strand bundle is shown in Fig. $2(6)$. In this model strands 1,2 , and 3 are not cooled.

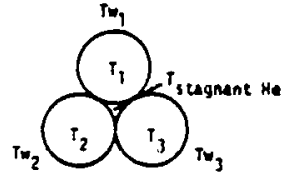

(a) TRIPLEX

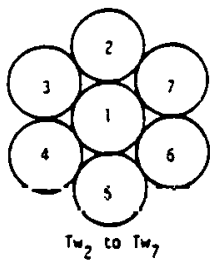

(b) 7 Strano gunole

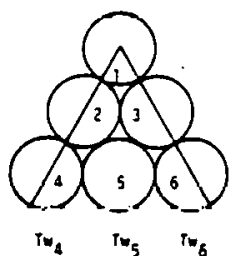

(c) $1 / 6$ of a 19 STRAND BUMare
Fig. 2. Recovery analysis models.
For the triplex if only two or one strands were cooled, the helium inventory (flow area) used in the calculation is the amount associated with the number of strands cooled. This is a conservative assumption. If the hel ium inventory associated with the entire triplex is available for removing the heat, regardless of the number of strands to be cooled, the recovery capability should be higher. For the 7 strand bundle the helium inventory associated with the outer six strands was used in the analysis. For the 19 strand bundle the helium inventory associated with all 19 strands was, however, used in the analysis.

The condition for recovery from an initially imposed normal temperature is that all the material nodes must be cooled down to below the current sharing temperature. If the helium is heated to a temperature exceeding the current sharing temperature before the solid material is cooled down, the strands will not recover. The helium inventory available for cooling has, therefore, an important effect on the recovery capability of the conductor.

\subsection{RESULTS OF ANALYSIS}

The design parameters of a typical $\mathrm{Nb}_{3} \mathrm{Sn}$ superconductor analyzed and illustrated in this paper are shown in Table 1. The results of the recovery analys is are shown in Fig. 3. The top solid curve shows the maximum recoverable normal temperature from which the triplex can recover at. various mass velocities, if all the strands were cooled. This is the nominal (or the ideal) condition in which the void area is uniformly distributed, so that all strands are cooled equally. For this particular conductor design configuration the maximum recoverable normal temperature is about $18.5 \mathrm{~K}$. The recoverable temperature decreases rapidly at mass velocity below about $1 \mathrm{~g} / \mathrm{s}-\mathrm{cm}^{2}$ where the heat transfer coefficient deteriorates rapidly as the helium flow rate decreases. The middle sol id curve shows the recovery capability of the triplex, if only two strands were cooled. The reduction in the maximum recoverable initial normal temperature is small. The bottom solid curve is for the case where only one strand was cooled. The recovery capability is seen to have reduced by about $1 / 3$ as compared to the nominal case. The recoverable temperature falls off rapidly at helium mass velocity beginning at about $3 \mathrm{~g} / \mathrm{s}-\mathrm{cm}^{2}$. A considerable increase in coolant pumping power is thus required in order to achieve a recovery capability from a normal temperature of about $13 \mathrm{~K}$. The results shown by the solid curves included the effect of the heat capacity of the stagnant helium inside the dead space between the strands. Without the stagnant hel ium the maximum recoverable initial normal temperature is reduced by about $0.3 \mathrm{~K}$. The effect is quite small.

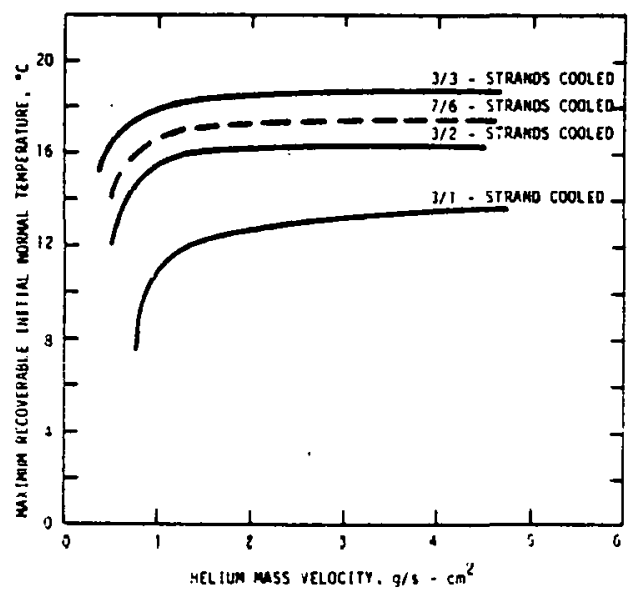

Fig. 3. Recovery capability for a triplex and a 17 strand bundle. 
TABLE 1

SUMMARY OF DESIGN PARAMETERS OF A $\mathrm{Nb}_{3} \mathrm{Sn}$ SUPERCONDUCTOR ANALYZED

\begin{tabular}{|c|c|}
\hline Superconductor & $\mathrm{Nb}_{3} \mathrm{Sn}$ - Bronze + Copper \\
\hline Peak Magnetic fleid & 12 Tesld \\
\hline Conductor Area & $5 \mathrm{~cm}^{2}$ \\
\hline Vold Fraction & 35: \\
\hline No. of Stronds & 567 \\
\hline Nominal Strand Diameter & $.0854 \mathrm{~cm}$ \\
\hline Codper-to-Non-Copder P.atio & 1.71 \\
\hline Hon-Copder Current Density & $8333 \mathrm{~A} / \mathrm{cm}^{2}$ \\
\hline Transport Current & $10.000 A$ \\
\hline Operating-to-Critical Current Density & 0.5 \\
\hline Superconductor Critfcal Temperature & $7.8 \times$ \\
\hline Current Sharing ienperature & $5.7 \times$ \\
\hline Initial Helium Temperature & $4.2 \times$ \\
\hline Strand insulation Thickness & $.003 \mathrm{~cm}$ \\
\hline Thermal Conductivity of Insulation & $0.25 \mathrm{w} / \mathrm{em}-\mathrm{k}$ \\
\hline Strands Compaction & App. $36 \%$ \\
\hline Copper Resistivity & $9.39 \times 10^{-8} \mathrm{n} \cdot \mathrm{cm}$ \\
\hline
\end{tabular}

For the seven strand bundle if only the outer six strands were cooled, the recovery capability is shown by the dashed curve in Fig. 3 . In this calculation the stagnant helium was not included in the model. The recovery temperature response is just about one degree or so below that of the ideal case, but still better than the case where only two strands of a triplex were cooled. This recovery capability is rather good under such an unlikely condition. For the 19 strand bundle with only the outer 12 strands cooled, the bundle would not recover at all, once it was driven to a normal state just above the critical temperature, even with a very high flow rate and high helium inventory. The result is not shown in the figure. Since the void distribution changes from section to section, such a bundling of strands should not occur over a long distance along the conductor. This condition would be most unlikely to occur in a long conductor.

Increasing the insulation thickness to such an extent that the insulation thickness to conductivity ratio is increased by a factor of ten, would reduce the recovery capability by about $0.9 \mathrm{~K}$. The effect is again small.

\subsection{CONCLUSIONS}

The effects of several off design conditions resulting from a possible non-uniform void distribution in a cabled superconductor on the cryogenic recovery capability of the conductor were studied. If only one strand in a triplex is cooled and the other two strands are not cooled, except by conduction to the one convectively cooled, the recovery capabiliticy of the trip. lex is reduced to about $2 / 3$ of that in a nominal cond 1 tion in which all three strands are cooled. The required coolant flow to obtain this level of recovery capability is about twice that for the nominal case. It is important in the initial design stage for the conductor to optimize the design parameters so to obtain the maximum possible thermal recovery margin. In addition, more coolant flow than that predicted by a nominal model could be specified to assure a sufficient recovery capability in sizing the cooling system. The amount of flow increment would depend on the degree of nonuniformity of the void distribution which may be. obtained from. inspection data of production cables. In the meantime, more experiments using an actual prototype conductor are needed to obtain applicable heat transfer, pressure drop and stability data for future design and analysis in order to assure a successful operation of the superconductors.

\section{ACXNOWLEDGMENTS}

This work was performed for the Office of Fusion Energy of the U.S. Department of Energy under Contract EG-77-C-02-4544.

\section{REFERENCES}

1. M. 0. Hoenig, et al.. "Supercritical Helium Cooled, Cabled; Superconducting Hollow Conductors for Large High Field Magnets," Proceedings of the Sixth International Cryogenic Engineering Conference, p. 310 (1975).

2. L. Oresner, "Stability-Optimized, Forced-Cooled, Multifilamentary Superconductor," IEEE Trans. on Magnetics, MAG-13, p. 670 (1977).

3. A. Y. Lee, "Thermal Design and Analys is of Superconductors for the Toroidal Field Coils of TNS," Proceedings of the Seventh Symposium on Engineering Problems for Fusion Research, p. 710 (1977).

4. A. Y. Lee, "Cryogenic Recovery Analys is of Forced Flow Supercritical Helium Cooled Superconductors," Adv. in Cryogenic Engineering, Volume 23, p. 235 (1978).

5. P. J. Giarratano, et a\}., "Forced Convection Heat Transfer to Supercritical Helium," Cryogenics, p. 384 (October, 1971).

6. M. 0. Hoenig and A. G. Montgomery, "Cryostability Experiments of Forced Cooled Superconductors," Proceedings of the Seventh Symposium on Engineering Problems for Fusion Research, p. 780, (1977). 